\title{
Representações de alcoolistas sobre a história de envolvimento com o álcool
}

\author{
Alcoholics representations about the history of involvement with alcohol \\ Representaciones de alcohólicos acerca de la historia \\ de la participación con el alcohol \\ Camila Elidia Messias dos SANTOS1 \\ Francisco de Assis MEDEIROS ${ }^{1}$ \\ João Antônio Machado BUZO² \\ Maria Fernanda Alda BARBOSA 3 \\ Bruna Almeida dos SANTOS ${ }^{4}$
}

\author{
${ }^{\mathbf{1}}$ Aperfeiçoamento em Psicoterapia Breve de Base Crítica, Centro de Promoção da Qualidade de Vida (PromoVi), \\ Faculdade de Odontologia, Araçatuba Universidade Estadual Paulista (UNESP), 16015-050 Araçatuba - SP, Brasil \\ ${ }^{2}$ Especialização Latu Sensu em Neuropsicologia, CENACE Centro Nacional de Cursos de Especialização, \\ 05409-011 São Paulo - SP, Brasil \\ ${ }^{3}$ Orientadora Social do Ação Jovem, CRAS - Centro de Referência da Assistência Social, \\ 16700-000 Guararapes - SP, Brasil \\ ${ }^{4}$ Graduanda em Psicologia, UNIP - Universidade Paulista, 16018-555 Araçatuba - SP, Brasil
}

\begin{abstract}
Resumo
Este estudo teve como objetivo investigar as representações sociais de alcoolistas sobre sua história de envolvimento com o álcool. Foram participantes desta pesquisa dez pessoas, com idade entre 28 a 60 anos, sendo uma mulher e nove homens, com nível de escolaridade média. Todos os participantes possuíam uma história de envolvimento com o álcool e frequentavam o A.A. (Alcoólicos Anônimos). As entrevistas foram realizadas em uma das sedes do A.A. em uma cidade no interior do Estado de São Paulo. Após o consentimento, foi utilizada entrevista semiestruturada para a coleta de dados. Por meio da análise dos depoimentos pôde-se observar que as representações do envolvimento com o álcool estão relacionadas à transgeracionalidade, dificuldade de relacionamento familiar e social e problemas profissionais. Concluiu-se que alcoolistas em abstinência possuem representações acerca de seu comportamento que remetem às suas vivências pessoais e sentidos que estes atribuem a elas. Ficando, então, clara a relação do ambiente para o início do comportamento de beber.
\end{abstract}

Descritores: Alcoolismo; Psicologia Social; Alcoólicos Anônimos.

\begin{abstract}
This study aimed to investigate the social representations of alcoholics, about their history of involvement with alcohol. Were participants in this study ten people aged 28-60 years, one woman and nine men, with medium level of education. All participants had history of involvement with alcohol and were A.A. (Alcoholics Anonymous) goers. Interviews were conducted in A.A. in one of the headquarter in a town in the state of São Paulo. After the consent, there were used semi-structured interviews to collect data. Through the analysis of the reports it could be observed that the representations of involvement with alcohol are related to transgenerationality, relationship difficulties with family, social, and professional problems. It was concluded that alcoholics in abstinence have representations about their behavior that refer to their personal experiences and meanings they attach to them. The results make clear the relationship of environment for early drinking behavior.

Descriptors: Alcoholism; Psychology, Social; Alcoholics Anonymous.
\end{abstract}

\section{Resumen}

Este estudio tuvo como objetivo investigar las representaciones sociales de los alcohólicos, sobre su historia de compromiso con el alcohol. Eran participantes en este estudio fueron diez La gente de edad 28-60 años, una mujer y nueve hombres, con el nivel la educación media. Todos los participantes tenían una historia de compromiso con el alcohol y los asistentes de AA (Alcohólicos Anónimos) Las entrevistas se llevaron a cabo en una de las sedes de AA en una ciudad en el estado de Sao Paulo. después de la consentimiento, se utilizó entrevistas semiestructuradas para recopilar datos. A través del análisis de los informes se pudo observar que las representaciones de participación con alcohol están relacionados con transgenerationality, dificultades en las relaciones problemas sociales y familiares y profesionales. Se concluyó que los alcohólicos en abstinencia Tienen representaciones acerca de su comportamiento que se refieren a sus experiencias personal y significados que atribuyen a ellos. Conseguir a continuación, desactive la relación de ambiente para la conducta de beber temprano

Descriptores: Alcoholismo ; Psicología Social; Alcohólicos Anónimos.

\section{INTRODUÇÃO}

O conceito de alcoolismo só surgiu no século XVIII através de duas referências. Segundo Gigliotti e Bessa ${ }^{1}$ a primeira vem de Benjamin Rush, um psiquiatra americano, que foi responsável pela célebre frase: "Beber inicia num ato de liberdade, caminha para o hábito e, finalmente, afunda na necessidade". A segunda, Thomas Toller, foi quem pela primeira vez, referiu-se ao alcoolismo como "doença". Na segunda metade do século XX o sistema de classificação do alcoolismo necessitou de critérios de maior confiabilidade e validade, passando por mudanças e começando a considerar os problemas com o álcool e outras drogas que não envolviam adicção ou dependência. $\mathrm{O}$ alcoolismo passa a ser considerado doença apenas quando o usuário apresenta tolerância, abstinência e perda do controle.

De acordo com Gigliotti e Bessa ${ }^{1}$, a CID-8 apresentava a adicção ao álcool como um estado de dependência física e emocional, com períodos de consumo pesado e incontrolável nos quais as pessoas experimentavam uma compulsão para beber e sintomas de abstinência quando cessava o consumo. Já a CID- $10^{2}$ classifica a síndrome de 
dependência como um conjunto de fenômenos fisiológicos, comportamentais e cognitivos, no qual o uso de substância ou classe de substâncias alcança uma prioridade muito maior para um determinado indivíduo que outros comportamentos os quais antes tinham maior valor.

Alguns traços de personalidade e funcionamento psicológico são afetados, dentre os quais se destacam a dependência afetiva, incapacidade de amar, comportamentos autoritários, percepção exacerbada, isolamento, negação permanente, planejamento obsessivo, lapso de memória e impotência sexual ${ }^{3}$.

Conforme Déa et al. ${ }^{4}$ o álcool é a droga mais utilizada pelos estudantes, seu consumo tem início precoce, uma vez que cerca de $50 \%$ dos alunos entre 10 e 12 anos já fizeram uso dessa droga. Quase $30 \%$ dos estudantes já utilizaram bebidas alcoólicas até se embriagarem. Os danos associados ao uso do álcool levam cerca de cinco a dez anos para aparecerem e estão diretamente ligados, nos jovens, a doenças sexualmente transmissíveis, uso de outras drogas, abuso sexual, baixo desempenho escolar, danos ao patrimônio, comportamento violento e confrontos entre gangues.

O consumo do álcool também pode estar ligado a fatores externos, como a algumas profissões com níveis maiores de tensão e estresse, a publicidade que estimula e valoriza o uso do álcool, a sociedade que é de opinião relativa e alienada; o preço acessível para todas as classes sociais e os interesses econômicos 5 .

O estudo de Oliveira et al. ${ }^{3}$, aponta para uma forte associação entre hábitos de beber do pai e os padrões do sujeito. Segundo eles, um processo de aprendizagem social ocorre, pois a criança cresce observando adultos lidando com seus próprios problemas através do uso de substâncias e aprenderá este comportamento como única habilidade de enfrentamento.

Atualmente, o alcoolismo não afeta somente a pessoa alcoolista, pois, além do comprometimento físico e mental do indivíduo, a doença repercute nos familiares que convivem diretamente com o alcoolista ${ }^{6}$. Segundo Messas e Vallada-Filho ${ }^{7}$, o alcoolismo pode incidir entre três a quatro vezes mais em parentes de primeiro grau, o que demonstra a presença do fator genético.

Campos e Ferreira ${ }^{8}$ declaram que quanto mais cedo o tratamento ou intervenção ocorrer, a fim de tratar o uso abusivo de álcool, melhor será para essa pessoa que terá menos chance de se tornar um dependente do álcool.

Assim, políticas para minimizar os efeitos dessa substância na saúde têm sido implementadas em diferentes países do mundo. A discussão tem girado em torno de políticas de melhor custo-efetividade, capazes de promover redução dos danos e dos custos socioeconômicos relacionados ao uso de bebidas alcoólicas ${ }^{9}$.

Conforme Campos ${ }^{10}$, os grupos de A.A. (Alcoólicos Anônimos) são um tipo de psicoterapia que tem demonstrado grande eficácia mundialmente. Tendo surgido como irmandade em 1935, em Akron, estado de Ohio, nos Estados Unidos, após uma conversa entre um corretor da bolsa de Nova York, Bill Wilson e um médico de Akron, Bob Smith. Estes passaram a perceber que por algum motivo não compreendido até ali, conseguiam ficar sem beber durante bons períodos depois que passavam algum tempo conversando e compartilhando seus problemas.

O A.A. dessa forma desempenha uma função importante ao constituir uma estratégia para combater o alcoolismo. Trata-se de um programa de recuperação, expresso nos "doze passos e doze tradições", cuja finalidade consiste em ajudar os alcoolistas a evitar o "primeiro gole" e a partir daí manter sua sobriedade ${ }^{10}$.

Esse apoio oferecido pelo A.A. faz a vinculação social de indivíduos que enfrentam o mesmo problema e possibilita a troca de experiências. Silva et al. ${ }^{11}$ apontam que as representações sociais são, de modo geral, entendidas como uma forma de conhecimento socialmente elaborada e compartilhada entre os membros de um dado grupo, em analogia para o estudo em questão, os alcoolistas, que tem como objetivo prático contribuir para a construção de uma realidade comum a um conjunto social.

Já segundo Alexandre ${ }^{12}$, a representação social ajuda a desvendar mecanismos de funcionamento de elaboração social do real, sendo assim fundamental no estudo das ideias e condutas sociais. Na medida em que ela consegue articular o processo social e o psicológico como um processo dinâmico, se tornou um instrumento importante da psicologia social.

Ainda, Jacques et al. ${ }^{13}$ discorrem que as explicações científicas através de representações sociais relacionam seu papel enquanto variáveis dependentes. Assim, diversas condições sociais, existentes em diferentes grupos e sociedades, trariam como consequências diferentes representações sociais que são, por sua vez, o resultado de necessidade de grupos ou sociedades ao lidar com novos fenômenos e novos problemas. O estudo realizado por Neves ${ }^{14}$ ressalta que é preciso compreender os modos moralizantes de representação do alcoolismo, seus efeitos sobre a construção das relações sociais e sua atribuição como fator dissolvente de unidades sociais fundamentais, como a família, ou perturbador do exercício de papéis básicos, como de trabalhador e esposo.

$\mathrm{O}$ presente estudo teve por objetivo descrever as representações de alcoolistas sobre a história de envolvimento com o álcool, tendo como base suas representações históricas, sociais, transgeracionais e as dificuldades encontradas ao longo de suas vidas.

\section{MATERIAL E MÉTODO}

Para a realização da pesquisa, foram selecionados 10 sujeitos de ambos os sexos entre 28 e 60 anos de idade, independente de religião, classe social, estado civil e escolaridade que possuíam história de envolvimento com o álcool e frequentavam o A.A. (Alcoólicos Anônimos) em uma cidade do interior de São Paulo. Teve como critério de exclusão os indivíduos que apresentaram dificuldades em compreender ou colaborar com a pesquisa, ou que não estavam de acordo com os critérios citados acima.

Utilizou-se o Termo de Consentimento Livre e Esclarecido, questionário semiestruturado contendo: idade, estado civil, escolaridade, se possuía deficiência, crença religiosa, etnia, situação socioeconômica, filhos, com quem residia e que idade entrou em contato com o álcool e entrevista semiestruturada com questões sobre a história da família do indivíduo com o álcool, a história do sujeito com o álcool e seus relacionamentos sociais e do histórico profissional do mesmo.

Após aprovado o projeto de pesquisa pelo CEPPE (Centro de Estudos em Psicologia e Educação), foi feito o primeiro contato com a instituição (A.A.) e com os membros para convite de participação, estabelecimento do vínculo e explicitação dos procedimentos para a realização do projeto. A coleta de dados se deu após a apresentação do Termo de Consentimento Livre e Esclarecido e dos cuidados e precauções éticas tomadas pelos pesquisadores relativos ao anonimato, garantia de sigilo, garantia de que os dados 
seriam utilizados somente para pesquisa e que seu depoimento poderia ser retirado a qualquer momento. Foi preenchida a ficha de dados, em seguida realizada a entrevista individual, em uma sala livre de ruídos onde as pessoas poderiam preservar sua identidade.

Deste modo, os dados encontrados foram analisados qualitativamente segundo categorias que compreendessem as falas dos participantes em relação aos objetivos da pesquisa. Tendo como pontos de análise: primeiro - a história dos indivíduos com álcool; segundo - a história com álcool e terceiro - a interferência dele nas ralações sociais; e a história de vida profissional, concordando com a análise de conteúdo ${ }^{15}$.

\section{RESULTADOS E DISCUSSÃO}

Para análise qualitativa foram pensadas categorias que pudessem trazer uma compreensão sobre as falas dos participantes em relação aos objetivos do trabalho. Foram pontos de análise: 1) A história dos indivíduos com álcool; 2) A história com álcool e a interferência dele nas ralações sociais; 3) A história de vida profissional.

1) História familiar com o álcool: Foram categorias do primeiro ponto de análise: a) Desajuste do ambiente familiar por comportamentos agressivos, b) Alcoolismo como algo transgeracional, c) Alcoolismo como não hereditário e d) Fator de sofrimento aos familiares.

1.a) Desajuste do ambiente familiar por comportamentos agressivos: Dentre os 10 entrevistados, 6 deles citaram o alcoolismo como o motivo de atos agressivos que causam transtornos a todos que estão ao seu redor, inclusive aos filhos.

\begin{abstract}
“... Quando eu comecei a beber, eu criei em mim uma compulsão que o médico diagnosticou com uma doença. Ah, eu bebi durante 15 anos, mas eu nunca tive coma alcoólico, essas coisas, a única coisa é que eu comecei a ser foi muito agressiva com todos, até com meus filhos. Tudo eu gritava, né, brigava e batia também. Eles ficavam sem saber por que eu sempre 'tava' brava com eles, não faziam ideia que era por causa da bebida, eram pequenos..." (F. 6).
\end{abstract}

1.b) Alcoolismo como fator transgeracional: Percebe-se que 6 entrevistados associam os hábitos de beber dos pais a seus próprios.

\begin{abstract}
"É, na verdade existe um histórico sim da parte materna, né!? É... é... a minha vó bebia, né!? O meu avô, marido dela bebia também e chegou o ponto que ele tomou veneno por conta do álcool ... meu irmão mais velho bebe, ele está sumido, nós não sabemos nem se ele tá vivo ou morto, ele se tornou um andarilho e tem eu que também fui premiado com essa pré disposição ao álcool. Ai, né?! na minha família só isso.” (M. 8).
\end{abstract}

1.c) Alcoolismo como não hereditário: Dentre os 10 entrevistados, 4 pontaram não possuir uma pré-disposição ou que a necessidade de se consumir álcool em nada tinha a ver com a relação familiar.

\begin{abstract}
"Não, não... mas o histórico de alcoolismo deles, da minha família assim nunca teve, meu pai é... posso dizer que meu pai tomava um aperitivo no final de semana, né... às vezes pra jantar, pra almoçar, mas assim é... não vejo como algo hereditário." (M. 1).
\end{abstract}

1.d) Fator de sofrimento aos familiares: Dentre os 10 entrevistados, 4 deles apontaram o álcool como algo que causa sofrimento em companheiros ou familiares.
“... mas mesmo assim tem mistério o alcoolismo, né?! Tem mistério, sabia? Porque eu bebendo é o seguinte, tinha desavença com a esposa e minha reação era ir pro bar e, qualquer coisa, eu ia pro bar, lá eu ficava tranquilo, sem saber que tinha mulher e tinha filho, né, mas eu fui aprendendo a lidar com o alcoolismo e a familia, né..." (M. 7)

Os fatores preponderantes nas falas dos sujeitos sobre suas histórias com o álcool envolveram principalmente: o desajuste familiar associado ao álcool, uma vez que este propicia o surgimento de comportamento violento e a transgeracionalidade do comportamento de beber.

De acordo com Bandura ${ }^{16}$, a teoria de modelagem do comportamento propõe que o processo de aprendizagem humano é influenciado por fatores externos e internos. Assim, a aprendizagem de comportamentos agressivos se dá por duas vias: observação de modelos reais e simbólicos nas pautas imitativas de agressão. Berns ${ }^{17}$ nos fala que este processo de aprendizagem é chamado por Bandura de aprendizagem vicariante, que se dá pela observação de outra pessoa e por suas consequências. Não é o suficiente que o comportamento ocorra e nem que suas consequências sejam positivas para o eliciador, mas estas têm que ser significativas para o imitador, a ponto de que em um momento posterior se torne um comportamento adaptativo.

Bandura $^{16}$ ainda nomeia reciprocidade triádica essa influência relacional entre ambiente, fatores pessoais e o comportamento. A influência exercida por esses fatores variam no indivíduo e de acordo com a situação, podendo assim um prevalecer sobre o outro. Ao contrário do pensamento tendencioso vigente nas décadas anteriores, estes padrões comportamentais aprendidos não são meras imitações, se tratam de modelações por estarem presentes significações dos reprodutores.

Messas e Valada-Filho ${ }^{7}$ corroboram com a teoria de Bandura ao expor que transgeracionalidade é caracterizada pelo modelo epigenético, onde a vulnerabilidade e o ambiente em que o indivíduo está inserido exercem, juntos, influência sobre este.

Ainda, segundo os mesmos autores ${ }^{7}$, o consumo do álcool pode se relacionar ao meio social, tornando-se uma maneira de aliviar as pressões causadas por problemas individuais. Assim, o alcoolismo é visto como uma via para alívio das pressões causadas no meio social e problemas individuais. Jovens e crianças que vivem em famílias que compartilham esta crença pouco desenvolvem repertórios para resolução de problemas e, assim, encontram resolução de seus conflitos consumindo dosagens de bebidas alcoólicas, resultando em um ciclo-vicioso.

Aqui pode ser apresentado um contra ponto ao que sugere Messas e Vallada-Filho ${ }^{7}$ quando denomina o 
consumo de álcool como resolutório de problemas, apesar do foco do alcoolista se desviar do problema, ele não o resolve, sendo assim, pode-se denominar o consumo de bebida alcoólica como uma fuga/esquiva. O entrevistado M.7 apontado acima, relata que bebe para esquecer o problema. No entanto, esse esquecimento é temporário, ou seja, enquanto se encontra alcoolizado, ao recuperar sua lucidez, o problema se apresentará e assim a falta de repertorio para resolução deste o encaminhará para a única via resolutória da qual se apodera: a fuga/esquiva.

Zalaf e Fonseca ${ }^{18}$ afirmam que a transgeracionalidade é um fator de risco para o uso de drogas, mas não isoladamente, necessitando de outras condições, como as já expostas, para que a dependência se instale. Desta forma, pode-se apontar o fator ambiental como atuante. A forma de inserção dessas pessoas nos processos de produção e reprodução social determinou os níveis de consumo e, assim, o acesso a bens materiais e alimentação foram prejudicados. Além disso, a falta de suporte familiar, educacional e de outros elementos expuseram a riscos e contribuíram para este processo. Quando adultos, os filhos de pais alcoólatras apresentam índices maiores de baixa autoestima, depressão e ansiedade, condições estas favoráveis ao maior consumo de álcool e outras drogas.

2) História com o álcool e seus relacionamentos sociais: Foram categorias do segundo ponto de análise: 2.a) Aprendizagem social e consumo de álcool; 2.b) Busca de outras drogas tidas como ilegais pela sociedade para a potencialização do efeito do álcool; 2.c) O uso do álcool como vivência social de felicidade/prazer e 2.d) Alcoolismo como fator de isolamento social.

2.a) Aprendizagem social e consumo de álcool: Dentre os 10 entrevistados, 6 deles tiveram a representação do alcoolismo como sendo uma aprendizagem social:

"Foi eu contato com álcool, e não' tava'...eu tomei sozinho, única coisa que aconteceu que eu me lembro, não lembro se eu tinha 12 ou 13 anos, eu fui buscar aguardente para os vizinhos meus que bebiam na calçada, né. Toda vez que eu ia buscar, eles me davam $30 \%$ da viagem, dava um real, 50 centavos eles me dava. Na época, não me lembro que dinheiro que era, na terceira viagem eu trouxe duas garrafas, uma pra mim e uma pra eles, porque eu via eles bebendo e estavam felizes ali, no meu primeiro contato com álcool eu fiquei com medo, não tive prazer não, bebi uma garrafa de pinga na época, Catira, lembro até o nome, só que não tinha ninguém da minha família em casa, ninguém presenciou..." (M. 2).

2.b) Busca de outras drogas tidas como ilegais pela sociedade para a potencialização do efeito do álcool: Dentre os 10 entrevistados, 3 deles apontam o álcool como porta de entrada para outras drogas.

“... E nesse período de 13 para 14 anos, só que aí através do álcool, eu já fui conhecendo outras drogas, né... eu sou cruzado, né... eu tenho problema com álcool e tenho problema com droga, né... o álcool pra mim foi a porta, né... eu comecei com álcool, né, nessa época aí eu comecei a fumar os primeiros baseadinhos, aí, entendeu? Eu sempre queria um efeito maior né... e aí a coisa foi ficando progressiva, né, meu... aí eu comecei a ter problema já, já de novo. No período de 27 anos 'tava' tendo problema sério mesmo com meu modo de beber, com meu modo de usar, né... é... essa coisa que eu falei, né, que no início me mostrou um mundo diferente, né, é..." (M. 1).

2.c) O uso do álcool como vivência social de felicidade/prazer: Dentre os 10 entrevistados, 6 deles apontam o álcool como algo que traz alegria e é assimilado com sentimentos de prazer àquele que o utiliza.

“... Na verdade, na verdade, quando tudo começou foi por causa da inveja que eu tinha dos outros, pois os outros bebiam e falavam, e dançavam, $e$ conversavam, e eram pessoas mais legais junto da turma. Eram pessoas que todos 'queria' por perto, principalmente as meninas, é claro. Era legal não ser tímido e ter coragem de fazer as coisas. Aí eu comecei a beber para poder ser assim também, 'legal'. E depois que eu descobri que dava certo, eu sempre tinha que beber pra poder ser alguém sem timidez, alguém que dançava e me divertia, caso contrário ficava no canto sem falar com ninguém..." (M. 9).

2.d) Alcoolismo como fator de isolamento social: Dentre os 10 entrevistados, 5 deles apontam o alcoolismo como fator de isolamento social.

“... Eu era muito antissocial, fazia bagunça em todos lugares que eu ia. Chegou num estado que minha família não era convidada pra mais nada, já que eu dava trabalho lá, todos excluíam minha família toda, minhas filhas e minha esposa não eram mais convidadas nem pra festa de parentes, $e$ de amigos muito menos porque se elas fossem é claro que me levariam, né? E quando eu começasse a beber estragaria a festa toda..." (M. 9)

Neste segundo ponto de análise, os fatores mais preponderantes abordados pelos sujeitos envolveram duas categorias, a aprendizagem social e consumo de álcool, já que os hábitos são adquiridos a partir do contato social e o uso do álcool como vivência social de felicidade/prazer.

Ferreira $^{19}$, sobre isso, aponta que as crenças do meio cultural, assim como o seus valores e atitudes, conduzem o indivíduo para o caminho da abstinência ou o uso de substâncias, como a bebida alcoólica. Essa premissa destaca então a importância do ambiente como determinante da conduta do sujeito. Assim, percebe-se através dos relatos que os indivíduos estavam inseridos em ambientes que cultuavam a ingestão de bebida alcoólica. 
Ainda, este padrão socialmente aprendido é defendido pelo modelo cognitivo-comportamental, sendo valorizado na sua aprendizagem e manutenção como aspectos do condicionamento clássico e operante, modelamento dos fatores cognitivos, que vão permitir que expectativas acerca dos efeitos do álcool e numerosos estímulos antecedentes e consequências reforçadoras, contribuam para a manutenção de um padrão do beber excessivo. Este modelo reconhece a interação entre os mecanismos comportamentais e genéticos, incluindo a aparente dificuldade dos alcoólicos, possivelmente de base genética, para discriminar os seus níveis de intoxicação.

Isso pode ser percebido no relato do entrevistado M.2 onde o beber foi reforçado pela aceitação de grupos sociais, inibição e sensação de prazer relatado por ele.

$\mathrm{O}$ ambiente social muitas vezes pode influenciar o indivíduo na associação dos eventos sociais ao álcool, como principal componente da mesma. $\mathrm{O}$ dependente assimila o álcool como algo prazeroso tornando-se mais difícil romper o ciclo do consumo.

3) Relato da vida profissional: Foi categoria do terceiro ponto de análise: 3.a) Álcool e problemas profissionais, 3.b) $\mathrm{O}$ álcool como fator de absenteísmo no Trabalho e 3.c) Vida profissional não afetada pelo uso de álcool.

3.a) Álcoole problemas profissionais: Dos 10 sujeitos entrevistados, 5 deles apontaram o álcool como responsável por problemas profissionais.

\begin{abstract}
“... Uma tragédia, né?! Eu não parava em emprego nenhum, não conseguia ter uma profissão, não tinha uma carreira adequada, normal. Teve só acidentes, vários acidentes, pra mim é assim, ou as pessoas trabalhando naqueles serviços mais baixos e sem registro. Enfim, uma vida deformada profissionalmente, eu acabei... hoje eu estou com 57 anos, acabei não conseguindo minha aposentadoria porque ainda me falta tempo de serviço, eu sempre falo: os 11 anos que eu passei bebendo são justamente os 11 anos que faltam pra 'mim' aposentar. Profissionalmente o álcool me deformou." (M. 4).
\end{abstract}

3.b) $O$ álcool como fator de absenteísmo no Trabalho: Dos 10 sujeitos entrevistados, 3 deles apontaram o álcool pelas faltas acometidas do trabalho.

“... Eu, tipo assim, na época eu trabalhei registrado, né, meu... 'mais' assim... eu faltava muito, né, cara. Às vezes, final de semana eu invernava, eu não tinha como levantar na segunda feira, não tinha essa disposição que hoje eu tenho pra ir trabalhar, aí isso começou a afetar na minha área de trabalho, né...trabalhei em metalúrgica, como pintor, né, e aí...sempre... me mandavam embora, aí o pessoal não fica, né, cara, aí comecei a trabalhar por dia, aí chegou um ponto que eu nem estava trabalhando também..." (M.1). 3.c) Vida profissional não afetada pelo uso de álcool: Dos 10 sujeitos entrevistados, 2 deles apontaram que o álcool não afeta sua vida profissional.

“... Na onde eu trabalhava, eu tinha uma mordomia que só. Eles me deixavam trabalhar do jeito que eu tava, me ofereciam tratamento é claro, 'mais' eu não aceitava não, falava que não precisava de ajuda deles não. Eles me ofereceram tratamento várias vezes, mas eu não aceitava não, eu achava que não precisava de ajuda, falava que saía daquela vida a hora que eu quisesse e sozinho, o que não é verdade. Trabalhei lá até me aposentar..." (M.9).

Os estudos de Andrade e Silveira ${ }^{20}$ relatam sobre a relação álcool e profissão e as dificuldades desta. Vaissman $^{21}$ aponta que o alcoolismo atinge entre $3 \%$ a $10 \%$ da população adulta e o classifica como o terceiro motivo para o absenteísmo no trabalho, passando a ser a causa mais frequente de aposentadorias precoces e acidentes de trabalhos, e a oitava causa para a concessão de auxíliodoença pela Previdência Social.

A partir dos discursos acima, os problemas relacionados ao álcool, que contribuem para as faltas no trabalho, são apontados pelo participante M.4, como: indisposição para levantar cedo devido à ressaca, perda de oportunidades de crescimento na empresa, problemas de saúde, deficiência física e deformação profissional relacionada ao fato de não ter uma profissão, muito menos uma carreira profissional.

\section{CONCLUSÃO}

Por meio da análise das respostas obtidas, concluiu-se que esses sujeitos representam a adicção de forma histórica e ligada à transgeracionalidade, situação percebida como precursora da condição com o qual se encontram, uma vez que em seus próprios lares presenciaram este modo de lidar com as situações diárias, apresentando déficit no desenvolvimento de repertórios sociais capazes de suprir necessidades ou terem suporte no enfrentamento de dificuldades ao longo de suas vidas.

É necessário frisar que o alcoolismo hoje é visto à luz do modelo epigenético. Sendo assim, fatores genéticos e ambientais se atrelam na manifestação da doença.

A representação social sobre o consumo de bebidas alcoólicas está muitas vezes associado ao prazer, felicidade e sociabilidade. No entanto, a mesma sociedade que viabiliza o consumo exclui aqueles que dele se tornam dependentes.

\section{REFERÊNCIAS}

1. Gigliotti A, Bessa M. Síndrome de dependência do álcool: críticos diagnósticos. Rev Bras Psiquiatr. 2004; 26 (Supl I):11-13.

2. Organização Mundial da Saúde. Classificação de transtornos mentais e de comportamento da CID-10: descrições clínicas e diretrizes diagnósticas. Porto Alegre: Artes Médicas; 1993.

3. Déa HRFD, Santos EN, Olic TB. A Inserção do Psicólogo no Trabalho de Prevenção ao Abuso de Álcool e Outras Drogas. Psicol ciênc prof. 2004; 24(1): 108-15. 
4. Carneiro FVP, Jorge MSB, Batista FLR. O alcoolismo e suas consequências: aspectos físicos e psíquicos. Rev RENE. 2005; 6(1): 51-61.

5. Oliveira MS, Werlang BSG, Wagner MF. Relação entre o consumo de álcool e hábitos paternos de ingestão alcoólica. Bol psicol, 2007; 57(127): 205-14.

6. Zanoti-Jeronymo DV, Carvalho AMP. Alcoolismo parental e suas repercussões sobre crianças e adolescentes: uma revisão bibliográfica. SMAD, Rev Eletrônica Sáude Mental Álcool Drog. 2005;1(2):1-15.

7. Messas GP, Vallada-Filho HP. O papel da genética na dependência do álcool. Rev Bras Psiquiatr. 2004; 26(Supl I):54-8.

8. Campos GM, Ferreira RF. A importância da legitimação social na (re) construção da identidade de um alcoolista. Estud Psicol. 2007; 24(2): 215-25.

9. Duailibi S, Laranjeira R. Políticas públicas relacionadas às bebidas alcóolicas. Rev Saúde Pública.2007; 41(5):839-48.

10. Campos EA. As representações sobre o alcoolismo em uma associação de ex-bebedores: os Alcoólicos Anônimos. Cad Saúde Pública, 2004; 20(5): 1379-87.

11. Silva SED, Padilha MI, Souza MJ, Araújo JS, Vasconcelos EV. Alcoolismo: Representações Sociais de alcoolistas. Revista Eletrônica Gestão \& Saúde. 2012; 3(3): 986-98.

12. Alexandre M. Representação Social: uma genealogia do conceito. Comum. 2004;10(23): 120-38.

13. Jacques MGC, Strey MN, Bernardes NMG, Guareschi PA, Carlos SA, Fonseca TMG. Psicologia Social Contemporânea. Petrópolis: Vozes, 2013.

14. Neves DP. Alcoolismo: acusação ou diagnóstico?. Cad Saúde Pública, 2004; 20(1):7-36.

15. Queiroz MS. O desafio do conhecimento: pesquisa qualitativa em saúde. Cad de Saúd Públ. 1992; 8(3): 342-4.

16. Bandura A. Social foundations of thought and action: A social cognitive theory. Englewood Cliffs, NJ: Prentice Hall; 1986

17. Berns RM. O desenvolvimento da criança. São Paulo: Loyola; 2002.

18. Zalaf MRR, Fonseca RMGS. Uso problemático de álcool e outras drogas em moradia estudantil: conhecer para enfrentar. Rev Esc Enferm USP. 2009; 43(1):132-8.

19. Ferreira APS. O consumo de álcool e comportamentos de riscos em estudantes do ensino superior [tese]. Aveiro: Universidade de Aveiro; 2008.

20. Andrade AG, Silveira CM. Dossiê: As faces do alcoolismo - Dependência: causas e tratamentos. Revista Psique Ciência \& Vida. 2010; 4(52):1-66.

21. Vaissman M. Alcoolismo no trabalho. Rio de Janeiro: Fiocruz; 2004.

\section{CONFLITO DE INTERESSES}

Os autores declaram não haver conflitos de interesse.

\section{AUTOR PARA CORRESPONDÊNCIA}

Francisco de Assis Medeiros

franciscomedeiros999@gmail.com

Submetido em 25/10/2016 Aceito em 05/12/2016 